\title{
"You Have to be Resilient": A Qualitative Study Exploring Advice Newcomer Youth Have for Other Newcomer Youth
}

\author{
Alexandra C. G. Smith ${ }^{1}$ (D) Claire V. Crooks $^{1}$ (D) Linda Baker $^{1}$
}

Accepted: 5 December 2021

(c) The Author(s) 2021

\begin{abstract}
Research infrequently includes the perspectives of vulnerable and marginalized youth. As the population of newcomer youth in Canada continues to grow, it is imperative that attention is devoted not only to challenges they experience, but also to resilience factors they perceive to support their adjustment and well-being. To address this gap, this qualitative research explored newcomer youths' experiences and advice for other newcomer youth who have recently arrived in Canada. Thirtyseven newcomer youth from two medium-sized cities in Ontario participated in focus groups. Participants ranged from 14 to 22 in age and identified mostly as female refugees from the Middle East. Through thematic analysis, five overarching themes were found across groups: (1) moving to a new country is hard, (2) maintain a healthy mindset, (3) take an active role in the adjustment process, (4) stay true to who you are, (5) and you are not alone. Youth described hardships that make moving to a new country difficult including lack of belonging due to racism and bullying, insufficient orientation to new systems, language barriers, and high levels of stress. Findings demonstrated youths' resilience, coping skills, and strategies to lead meaningful lives. Youth discussed resilience strategies such as maintaining a connection with home culture and religion, reframing thinking to be positive, receiving emotional support, accessing community support at newcomer agencies, and building language proficiency. Findings provide implications for professionals working with newcomer youth and reflect the importance of addressing structural barriers and racism. The opportunity for newcomer youth to share experiences as experts in research may also help to promote resilience.
\end{abstract}

Keywords Refugee $\cdot$ Immigrant $\cdot$ Youth $\cdot$ Qualitative $\cdot$ Focus groups $\cdot$ Well-being

Immigration accounts for approximately two-thirds of the population growth in Canada. (Statistics Canada, 2017a). While the economic class of immigrants (i.e. those who have specific occupational skills and experience to support the needs in Canada's labor market) makes up the greatest proportion of newcomers admitted into the country each year, the Canadian government notably increased the number of refugees to be resettled into the country. An influx of nearly 100,000 refugees resettled in Canada between January 2015 and March 2018, many of whom were under the age of 18 (Child and Youth Refugee Research Coalition, 2018). Global trends reveal that we are presently experiencing one of the largest humanitarian crises in history as the number of forcibly displaced persons worldwide has grown substantially,

Alexandra C. G. Smith

asmit564@uwo.ca

1 Faculty of Education, Western University, 1137 Western Road, London, ON N6G 1G7, Canada reaching 70.8 million by the end of 2018 (United Nations High Commissioner for Refugees, 2018). As part of Canada's humanitarian commitment to resettle those most at risk, the country had plans to welcome over 30,000 refugees in 2020 (IRCC, 2020). The term newcomer will be used throughout this paper as an inclusive category that describes individuals who have been in the country five years or less.

\section{Newcomer Youth and Risks}

Despite the increasing population of young newcomers in Canadian communities, there is a lack of understanding and support from residents and professionals working with these youth, particularly for refugee youth, as these young people can face significant challenges related to emotional, linguistic, academic, and social functioning (Guo et al., 2019). There are unique factors related to migrating as a youth that warrant the need for research addressing how 
to support these young people and their healthy development in a timely manner. Refugee and immigrant youth are required to adapt to new environments, navigate new culture and language, and reconstruct their social networks while moving through important developmental stages, during which a number of biological, cognitive and psychosocial changes occur that can coincide with resettlement stress and impede well-being (e.g. puberty, identity formation; Juang et al., 2018). It is during this period of life that approximately half of mental illnesses surface, and these can have lasting impacts throughout the life course (World Health Organization, 2019). Although physical and mental health of various newcomer populations tends to be superior to the native-born population upon arrival, a phenomenon known as the healthy immigrant effect, this advantage diminishes and health tends to deteriorate with time spent in Canada (Beiser et al., 2002; Vang et al., 2017; Xu \& McDonald, 2010). Some research has shown that immigrant youth in Canada report higher rates of psychological distress than Canadian-born peers (Hamilton et al, 2009). Furthermore, rates of post-traumatic stress disorder, depression, and anxiety are cited as being elevated in refugee populations (Derluyn \& Broekaert, 2007). As such, there has been an increasing focus on the well-being of newcomer students in Ontario schools to assist with the resettlement process (School Mental Health-Assist, 2016).

Within a multi-level framework, there is a dynamic interaction of factors (e.g. demographic, social, cultural, and psychological) that operate at multiple levels (i.e. individual, family, community, and macro) and impact youth outcomes (see Mawani, 2014). Common stressors for an individual and within the family unit post-migration include but are not limited to loss of close relationships, loss of lifestyle, uncertainty about immigration status, change in socioeconomic status, change in cultural norms, and proficiency in the host country's language (Pickren, 2014). Difficulty making friends and adjusting to the school setting are frequently reported stressors faced by young newcomers in Canada (Guo et al., 2019). Factors such as socio-linguistic barriers, racism, bullying, and isolation can hinder their ability to form important relationships in schools and communities (Hadfield et al., 2017). Negative media portrayal and hostilities related to anti-immigration rhetoric, similar to that in the United States, are an ongoing challenge in Canada, especially in relation to Islamophobia (Woodley et al., 2018).

\section{Newcomer Youth and Resilience}

There is a paucity of research examining how recent newcomer youth adjust and cope in Canada as research and support has been predominately deficit-focused (Mawani, 2014). There is a need to explore strengths-based approaches with a focus on natural resilience to help empower newcomer youth as they respond to stressors. Newcomer youth possess profound strength and resilience factors that help them adjust to new environments.

Resilience is complex and varies across culture and context (Liebenberg \& Theron, 2015; Ungar, 2008). In the literature on young refugees, individual characteristics (such as internal locus of control, cognitive skills, and emotion regulation) and coping strategies (such as problem-solving and sense of agency, future, hope, and growth) have been suggested as protective factors contributing to resilience outcomes (Betancourt \& Khan, 2008; Este \& Van Ngo, 2011. In addition, factors operating at different levels of a youths' social ecology, including attachment with caregivers, family stability and caregiver mental health, reduction of linguistic barriers, social support, acceptance, and sense of belonging in community and school environments can promote resilience (Betancourt \& Khan, 2008; Este \& Van Ngo, 2011). Although the impact of migration on identity is not well understood, maintenance of cultural identity (e.g. speaking native language in the home, religious practices and pragmatic strategies such as dress and diet) also appears to be an important resource for resilience (Pickren, 2014). Further investigation related to how newcomer youth navigate through the process of adjustment is necessary, particularly from the perspectives of youth themselves.

\section{Present Study}

The importance of youth voice both in research and policy making has been acknowledged, though young people often still feel ignored or dismissed when sharing their views about issues central to their lives (James, 2007; Shamrova \& Cummings, 2017). Young people have received less attention than adults as experts of their own worlds, especially with respect to participant experiences in research (Liegghio et al., 2010). This is especially true for marginalized and vulnerable populations. To address this gap, the primary purpose of this exploratory paper was to shed light on refugee and immigrant youths' expressed perspectives on advice and coping strategies to overcome the challenges they face after relocating to a new country. Newcomer youths' lived experiences can provide a richer understanding of adjustment in the Canadian context and may promote action in relation to larger issues (i.e. social; system-level). Engaging the voices of newcomer youth to share their advice for other newcomers may also promote empowerment and be used to inform efforts targeting their adjustment and well-being that is more responsive and culturally appropriate (Bergnehr \& Zetterqvist Nelson, 2015).

Focus groups were selected because they are well-suited to provide insight into participants' thoughts and feelings 
(Stewart \& Shamdasani, 2014). Interaction among participants in a focus group can generate collective insight from shared experiences and difference of opinions regarding relevant topics in their lives (Smithson, 2000). Additionally, focus groups have the potential to promote empowerment among marginalized groups as a result of the collective experience (i.e. discussion around relevant life issues and experiences with others from similar social position in terms of knowledge, language, and framework), and can reduce power differentials between the researcher and participants, potentially creating a less threatening environment to share their views (Bagnoli \& Clark, 2010).

\section{Method}

\section{Participants}

Four focus groups were conducted with 37 newcomer youth in Ontario communities during fall 2019. A purposive sampling strategy was used to recruit youth who met the following criteria: aged 14-24 years; identified as a refugee or immigrant; could speak English well enough to engage in back-and forth-conversation; and attended programming at immigrant-serving organizations. Table 1 displays demographic characteristics of the participants. Youth ranged from 14 to 22 in age $(M=17.1 ; S D=1.7)$. More youth identified as female (65\%), entered Canada as refugees (65\%), and had resided in the country for less than four years $(M=2.89 ; S D=1.9)$. The largest proportion of youth came from countries in the Middle East (73\%). The study was approved by our University's Research Ethics Board.

\section{Procedure}

Participants were recruited through staff with whom they were familiar from two immigrant-serving organizations located in two medium-sized cities in Ontario. Focus groups were conducted at these organizations. The purpose of the study and the conditions for participation were discussed with youth prior to focus groups. Parental consent and youth assent were obtained for youth 16 years and under; youth 16 years and older signed their own consent forms. Youth were also informed about the importance of privacy and agreed to keep all information shared in the focus groups and the identity of other participants confidential. Once informed consent was obtained, participants filled out a short demographic questionnaire.

Prior to each focus group, an icebreaker activity was utilized to build rapport and allow youth to become acquainted with other youth, the moderator, and the note taker. It appeared that many youth knew each other, likely through the programs offered at the organizations. The icebreaker
Table 1 Demographic Characteristics of Focus Group Participants

\begin{tabular}{ll}
\hline & $(\mathrm{n}=37) ;$ \\
& count $(\%)$ \\
\hline Age (years) & \\
$14-15$ & $4(11)$ \\
$16-17$ & $20(54)$ \\
$18-19$ & $10(27)$ \\
$20-22$ & $3(8)$ \\
Gender & \\
Female & $24(65)$ \\
Male & $13(35)$ \\
Status entering Canada & \\
Immigrant & $13(35)$ \\
Refugee & $24(65)$ \\
Ethnicity & \\
African & $8(22)$ \\
Latino & $2(5)$ \\
Middle Eastern & $27(73)$ \\
Time Residing in Canada & \\
Less than a year & $4(11)$ \\
1-2 years & $8(21)$ \\
3-4 years & $21(57)$ \\
More than 4 years & $4(11)$ \\
\hline
\end{tabular}

activity involved a series of low-risk statements during which youth were asked to respond by standing up if the statement applied to them (e.g. I am the youngest person in my family; I like to dance). After that, an audio recorder was turned on and a semi-structured interview guide was utilized to gather information from youths' perspectives about challenges related to their well-being and relationships, advice for other newcomer youth who recently arrived in Canada, and programs, activities, events, and people that have been helpful in Canada. A primary question, "What advice would you give to someone your age who is moving to Canada," provided rich data for the present study, though applicable responses to other questions were included in the analysis. The focus groups were conducted in English by the first author and a note taker was present. Discussion ranged from 30 to $55 \mathrm{~min}$ across the focus groups. Table 2 provides information pertaining to group make-up. Participants were compensated with a $\$ 20$ gift card.

\section{Data Analysis}

The first author transcribed interviews with Trint voice-totext software. After the first author reviewed and revised the transcriptions based on the audio recordings, a research assistant examined the transcriptions against the audiotaped interviews. The transcriptions were edited slightly for clarity and by removing word repetitions to make the text 
Table 2 Focus Group Information

\begin{tabular}{|c|c|c|c|}
\hline & $\begin{array}{l}\text { Number of } \\
\text { Participants }\end{array}$ & Gender & Ethnic Makeup \\
\hline Focus Group 1 & 10 & $\begin{array}{l}5 \text { Male } \\
5 \text { Female }\end{array}$ & $\begin{array}{l}\text { Primarily African } \\
\text { (Congolese, Ethiopia, } \\
\text { Namibia \& Tanzania) } \\
3 \text { Middle Eastern }\end{array}$ \\
\hline Focus Group 2 & 10 & $\begin{array}{l}5 \text { Male } \\
5 \text { Female }\end{array}$ & $\begin{array}{l}\text { Middle Eastern (All from } \\
\text { Syria) }\end{array}$ \\
\hline Focus Group 3 & 8 & All Female & Middle Eastern \\
\hline Focus Group 4 & 9 & $\begin{array}{l}3 \text { Male } \\
6 \text { Female }\end{array}$ & $\begin{array}{l}\text { Primarily Middle Eastern } \\
2 \text { Latino } \\
1 \text { African }\end{array}$ \\
\hline
\end{tabular}

more readable. Thematic analysis was conducted to identify patterns across the data and to provide a rich and in-depth description of the dataset (Braun \& Clarke, 2006). Due to the exploratory nature of this study, an inductive approach (versus 'theoretical' thematic analysis) was utilized with a semantic and realist orientation. Themes were data-driven (i.e. did not fit into a pre-existing coding frame) and identified within explicit meanings of the data to remain close to participants' meanings (Clarke et al., 2015).

The first author familiarized herself with the data, coded the data in relation to the research questions, organized the data into meaningful groups or themes, reviewed the themes, and produced names based on content within each theme (Braun \& Clarke, 2006). Specifically, the first author read and re-read transcripts to become familiar with the data and made notes and reflections about content that stood out to her. Data was then coded line-by-line using an open-coding approach with the aim of summarizing participant responses into short statements in relation to the research questions. The first author organized codes into meaningful categories. In this sense, themes and sub-themes were developed based on similar perspectives voiced by multiple participants. The second and third authors reviewed and discussed the first author's coding process and initial development of themes with examples from the data, and together the authors agreed on the final themes and their labels. The first author is finishing her doctorate degree and has used Braun and Clarke's thematic analysis approach to analyze data on two occasions prior to the present research, while the second and third authors are registered psychologists and faculty members at an Ontario University with extensive research experience.

To increase trustworthiness in the data, the following criteria were employed: credibility, transferability, dependability, and confirmability (Shenton, 2004). Strategies used to increase confidence in credibility of the data were member checking, reflexivity, and peer debriefing (Anney, 2014). More specifically, the first author summarized the discussion at the conclusion of each focus group to allow participants the opportunity to confirm the accuracy and completeness of the summary, kept a field journal to log each step of the process as well as her reflections and reactions throughout, and presented the findings to the second and third author to receive additional perspectives. The first author additionally conducted site tours at four immigrant-serving organizations (including the two involved in this study) to better understand services provided and youth experiences, and facilitated a healthy relationships program with a group of newcomer youth in a high school setting. This experience provided her with insight into newcomer youths' cultures and contexts, and helps to bolster trust in the data.

A purposeful sample was selected to allow for transfer of the findings, while an audit trail was used to explain research decisions, activities, and observation notes and allow for transparency and increase dependability of the findings (Anney, 2014). To increase confirmability, the first author intentionally worked to be open and transparent in terms of her interpretations and impressions to ensure that findings were representative of the participants' narratives rather than her preconceived ideas and biases (Shenton, 2004).

\section{Results}

The five overarching themes found across groups reflected participants' experiences and advice for other newcomer youth who have recently arrived in Canada. The first theme acknowledged the challenges associated with moving to a new country. The second and third themes demonstrated how youth can take an active role in the adjustment process to overcome challenges and positively reframe their thinking. The fourth theme reflects perspectives that newcomer youth should stay true to who they are by being authentic and resisting societal pressure to change. The final theme provided reassurance that youth are not alone and described how to receive support.

\section{Moving to a New Country is Hard}

The first theme relayed messages that participants recognized adjustment will be hard initially due to challenges navigating a new country combined with typical teenager struggles. A number of youth spoke of stressors that occurred before their move to Canada that they are still trying to cope with (i.e. hardships and losses back home, and difficulty letting go of the past). In this sense, participants validated the challenges that youth may encounter. One youth said:

I'm gonna say the first years will be hard. I know that, like they're going to cry, they're going to be lost. That's going to happen, like of course...I lost a lot. I cry a lot 
and even in school, I lost in school... And so the first year will be hard. (Focus group 2)

As this quote revealed, one specific reason why moving to Canada is hard relates to "feeling lost" while adapting to new environments such as school systems and their community, as well as having to learn new language and rules in Western culture.

Many participants described feeling misunderstood and identified Canadians, teachers, friends, and even parents as individuals who did not understand them. For instance, a participant stated, "Your teacher doesn't know what you have been [through], or what's happened to you, or why you want to be alone, or why you are excited" (FG-2). This message was very important because participants commonly reported feeling as though they don't belong in Canada due to a lack of acceptance from members of the receiving society, racism, discrimination, and bullying:

Some people just say, "why did you come here? You can't talk English, you can't learn anything." And then the other day I heard the man..."why did you come here, like all you people." There was like, you know the Indian people, like he was talking about them. Like, "go back to your country." (Focus group 4)

Youth described feeling "like you're not good enough" in comparison to native-born peers who understand the way things are and having difficulties making connections and trusting people from the receiving country. These types of experiences, along with numerous acculturative stressors upon resettlement contribute to feelings of loneliness.

In addition to the challenges associated with being a newcomer, participants spoke about how they experience stress that is typical for any youth (e.g. pressure to do well in school), along with bullying and peer pressure in their social interactions, and exposure to risk behaviour (e.g. substance use). For instance, one youth explained:

Bullying is one of the biggest things that- and still not stopping until now and I feel like people around our age is the ones suffering the most because when you're in grade school, everyone's just playing. But high school is when everything happens and that's when we all can relate to each other. Everyone experienced it and went through it, I'm sure. (Focus group 1)

In sum, these challenges demonstrate how moving to a new country is hard during this developmental period of life, particularly because of differences between their old country and new country, and feeling misunderstood. Despite challenges that newcomers experience, participants spoke of resilience and courage in ways that will be discussed in the following themes.

\section{Maintain a Healthy Mindset}

The second theme captured advice related to the importance of having the right mindset to stay strong and keep going when times are hard. Participants used phrases such as "have faith in yourself", "don't give up fast", "try your best", and "go for it" to encourage youth to persevere through challenges. A few participants also spoke about having patience when adjusting because learning takes time. Participants shared examples of how it can be easy to think negatively, but how youth should try to reframe such thinking to be more positive to keep a healthy mindset:

But what keeps me positive... My parents come here for me to study. Why am I always being negative to stuff...I try to think about something to let me reach my goal. Yeah, I think thinking is the most like [important] part that's let your brain [be] healthy or not healthy. (Focus group 3)

Similarly, participants recognized the benefits of reframing their experiences to be able to grow from the past and look to their future:

"Yeah, we try to like to- like the thing that's happened, to not feel like- to be a positive thing in our future, not a negative thing. We learned from it. Not like just every single time I sit and think about it and start to cry...No, just live it a positive thing, not a negative." (Focus group 3)

Another youth provided a similar example, that included the concept of life in Canada being a fresh start, and opportunity to do things differently:

"And if you had tried something in your country and it didn't work, you can try it here maybe. You try something different. If you stopped studying or I don't know how I say it- but if you stopped studying, maybe to work, maybe you came to here and then stopped work and continued your studying to make your life better." (Focus group 2)

Thus, maintaining a healthy mind to persevere by reframing thinking to find positives and looking to the future are ways in which participants suggested that newcomer youth could weather the challenges they face upon arrival in Canada.

\section{Take an Active Role in the Adjustment Process}

This next theme illustrates some ways youth might actively navigate a new country. In other words, strategies for youth to embrace their move to a new country. As one participant speaking about cultural nuances said, "All the rules kind of change" (Focus group 2), and youth should try to be open 
to learning about their new country, asking questions, and building connections.

Participants suggested being willing to learn about Canada, its people, culture, and social rules. One participant suggested, "open your mind" to Canada and another said, "like be with other people...don't say no it's not good, this way not good. Try to understand other people, other culture." (Focus group 4). A number of youth stressed the importance of learning English. Youth associated understanding the language with adjustment and success, and acknowledged the barriers that poor language proficiency presents:

Speak your language. But we have to have a time where we speak English too. Cause I don't see it happen a lot. And I am not saying you shouldn't speak your language. Cause I also like speaking my language, but I want people to improve, how to speak you know. At the end of the day, they don't end up working because of their language barrier. (Focus group 1)

Taking an active role in the adjustment process also included asking questions and seeking help when they are unsure or confused:

So, I think asking just so many question would be the best. Yeah, and just to know about everything before you actually do any steps. (Focus group 3 )

Participant responses suggested there is a lot to learn in Canada that is different than their home country and youth should take steps to seek out information that can support their adjustment. Lastly, some participants indicated that taking initiative to build connections with others will support youths' adjustment and well-being as one youth explained, "If you be social with people like that, I think it would be easier" (Focus group 3). Thus, participants felt that it is important to learn about the country (i.e. rules and the language), and that asking questions and interacting with Canadians were some ways that youth can take an active role to make for a smoother transition.

\section{Stay True to Who you Are}

The next theme reflects participants' views that youth should stay true to who they are and who they want to become. In this sense, participants wanted youth to know that their background identity is valid and to have self-assurance as they form their identity in a new country. Two subthemes captured participants views about how to manage when faced with invalidating types of messages that suggest youth are not welcome and are "different". These are: (1) Resist the pressure to change, and (2) Be authentic.

\section{Resist the Pressure to Change}

Participants acknowledged that youth will experience pressure to change their identity (e.g. culture, religion, appearance) and behaviour. One example that participants shared suggested that this pressure is often because of mainstream forces, but that they should resist the urge to change:

It could also be like you know we wear hijabs, bigger clothes, like long sleeves, stuff like that... and you kind of see the discrimination in some people that are wearing. You kind of feel like should I change too, should I like take it off. So, I hope like you find it in yourself to do your own stuff. To fit into your own style. Don't change your culture or religion just because it's being discriminated against. Fight for it instead. (Focus group 1)

Thinking about the future, one participant in the second focus group summed it up as, "If you have a dream and you came here to Canada, do your dream and don't let people go into your dream. Like your dream is to do this, do it." This subtheme intersects with the next subtheme, be authentic.

\section{Be Authentic}

The perspectives reflected in this subtheme suggests that youth can be authentic and still find their way to fit into Canadian society. A narrative present among participants was that it is okay to be different. Participants mentioned that youth have different backgrounds and culture, but that they can still belong in a community where they live: "Just fit in, in a different way. Like you just don't have to fit into that way that they want you to. You can just fit in with the community in a different way" (Focus group 3). Participants also suggested that that with time youth can "find the right people" to form relationships with. One participant from the second focus group shared, "Try and find people that likethey're the same kind as you. Yeah, try to find people that will treat you good, and like they will let you follow your dream and make your future like better."

Furthermore, the idea that youth ultimately decide who they want to be and make choices for themselves in Canada as a result of the laws that govern the country was presented by one participant who stated, "Like it's a free country. Do whatever you like, learn whatever you want. No one forces you to do this, or to go to that religion, or they don't accept you. Like it's good. Canada- it's multiple culture" (Focus group 4). Overall, participants' advice to other newcomer youth to stay true to who they are can be achieved by resisting the pressure to change their identity and accepting individual differences to live authentically. 


\section{You Are Not Alone}

The final theme reflects participant views about how to address stressors they experience. Specifically, youth explained how talking to loved ones and visiting newcomerserving organizations can help. Participants wanted youth to know that there are other youth who have been in the "same position" and experience the "same difficulties." Therefore, newcomer youth do not need to be alone in their journey. Two subthemes provide suggestions and strategies to reduce isolation: talking helps and access support at newcomerserving organizations.

\section{Talking Helps}

Participants discussed how talking to trusted individuals can help to address challenges they face. Some youth explained that simply talking about what youth feel with someone can relieve stress and help them to feel better: "Yeah, so you would talk and then you would feel better, and then you would feel like something just went away" (Focus group 3). Similarly, a youth from another focus group said, "So I think for me, what I like to do is I talk about it with someone, and it just feels like a hundred big things like lift out of my chest" (Focus group 1). Friends, parents, and extended family were noted as those whom youth typically approached to talk, although one participant explained that when others become aware of the struggles youth have, they may be able to assist youth in seeking out more formal support:

A lot of people, they came from a country who have war...so I think if we talk to them and be friends with them and then show them there is a lot of um, places they can go... and like talk [to] them and then that helps them... I think if we show them, and taught them about the centre or about the place, they can help them. (Focus group 2)

Youth also mentioned consequences of keeping feelings and struggles to oneself, including pain and its potential worsening:

Find somebody to always like, you know, to tell. Just don't keep things in because it's really painful when you just keep it in, so just find somebody. (Focus group 3)

This strategy was perceived to help youth feel heard and reduce feelings of loneliness, and this intersected with the next subtheme.

\section{Access Support at Newcomer-Serving Organizations}

In addition to talking to trusted individuals, participants spoke about the benefits of accessing support and resources at newcomer-serving organizations. These organizations were described as contributing to the development of social networks and being a place to receive social support. As a participant explained, programming at newcomer organizations brings people together of similar and different backgrounds and supports the development of connections with others:

Cause everyone that comes here is newcomers, right? So, it actually helps you to relate, "oh I'm not the only new person here with the language and with the culture." So, I think these programs are the most helpful... In school, you know this culture is here and that culture is over there. There's that people, that people, they all like separated [from] each other, and for us too, we couldn't even learn English, cause we all sit with our people... like there was no multiculturism. But in this kind of places, there is the unity he was talking about. The multiculturalism. (Focus group 1)

Other youth spoke about organizations' efforts to provide a warm, friendly environment:

They all try to make you feel like you're at home... Even like any newcomers comes here, they try to make them feel like welcome. Meet new friends, like they're very helpful in here. (Focus group 4)

Newcomer organizations were mentioned as offering newcomer youth social support, through emotional, informational, and practical means. Some youth spoke about meeting supportive people who provided information and assistance overcoming barriers related to adjustment (e.g. settlement worker showing youth around the city), while others discussed how programming in these organizations can create a safe space where youth feel comfortable receiving support:

There was also that program after school for like - it's just like homework club. And also, if you don't want to do your homework, you can just like sit down and have a conservation and there's actually people to just talk to, practice your English and stuff, because you can't really find any new people in school to talk to in your daily life or something because you're just new to Canada. So, like you would just sit and read after school and talk or do our homework, help each other. (Focus group 3)

Overall, the final theme encouraged youth to seek out components of community resilience, to access and connect with supportive people and resources to reduce feelings of isolation. 


\section{Discussion}

The present study explored newcomer youths' experiences and as well as their advice and perceptions of what would be helpful for recently arrived youth in Canada. Participants across groups discussed challenges previously identified in the Canadian literature such as lack of belonging due to racism and bullying, insufficient orientation to new systems (particularly school practices and norms), language barriers, and high levels of stress (Edge et al., 2014; Guo et al., 2019; Hadfield et al., 2017; Selimos \& George, 2018). Participants' advice for recently arrived newcomer youth to promote adjustment and well-being amidst difficult circumstances adds to the relatively limited literature on resettlement experiences of young newcomers in Ontario in a way that prioritizes the views and experiences of young people. Participants provided recommendations that ranged from validation of challenges to encouraging messages and strategies.

Similar to past research, findings demonstrate that newcomer youth "feel lost" and experience a lack of belonging in Canada during their first years of resettlement (e.g. Guo et al., 2019). From youth perspectives, stressors such as lack of English proficiency, racism, and "new rules" can make youth feel worthless in comparison to Canadianborn peers and can contribute to lower self-esteem as found in past research (Edge et al., 2014). Despite efforts being implemented to welcome newcomers and support their well-being in Ontario schools (School Mental HealthAssist, 2016), examples of racism and discrimination that were shared by youth often occurred in school settings. This is consistent with previous literature suggesting that school systems are ill-equipped to support transition and address the mental health needs of newcomers as they enter Canadian schools (Ratković et al., 2017). Scholars in other Canadian provinces have found that a more thorough familiarization to school systems is needed for newcomer students, particularly refugee youth who may have experienced disrupted schooling (Li et al., 2017).

Participant recommendations aligned with factors linked with resilience and positive acculturation in previous literature including maintaining a connection with home culture and religion, receiving emotional support from family and friends, accessing community support at newcomer agencies, reframing thinking to be more positive, and building language proficiency (Ontario Centre of Excellence for Child and Youth Mental Health, 2015; Pieloch et al., 2016; Pickren, 2014). Similarly, a sense of community and communal self, as well as reframing thoughts to promote hopefulness for the future were viewed as resilience factors from the perspectives of refugees in the United States coping with trauma and hardship in their lives (Goodman, 2004). Youth advice supported the notion that resilience factors extend beyond individual characteristics to one's family, school, community, and society (Pieloch et al., 2016). For instance, the benefits of programs at newcomer-serving organizations including having a safe place to develop relationships and a sense of community can promote resilience at the community level (Edge et al., 2014).

One unique finding was youths' advice to talk about their struggles and access support, with one participant even referencing formal mental health services. This was positive given that newcomers (especially those of a non-Caucasian descent) underuse formal supports (e.g. Boukpessi et al., 2021; Kirmayer et al., 2007) and may be more likely to use distraction and suppression as ways to cope, which can be problematic in the long run (Goodman, 2004). The fact that many youth participants also discussed maintaining their home culture despite feeling pressure to change was an important finding as identity formation is prominent during this stage of life. Previous work has found that well-adjusted newcomer youth tend to have a strong ethnic identity and find balance in maintaining their home culture and adapting to the culture they are immersed in (Costigan et al., 2010; d'Abreu et al., 2019).

\section{Implications}

These findings have several implications for policy makers and professionals working with newcomer youth. From a social-ecological perspective it is acknowledged that resilience develops not only because of individual psychological processes, but also as a result of "social process that reside in relationships among people, systems and institutions at the level of families, neighborhoods, communities, and organizations, governments and transitional networks" (Kirmayer, 2014, p. vii). Youth identified challenges related to systemic problems outside of their control (e.g. racism and bullying) that make adjustment very stressful and cause them to feel like they don't belong in Canada; yet, the manner in which youth spoke suggested they feel the onus is on them to be resilient and thrive, rather than on the receiving society to support their well-being and relationships.

From a policy-making perspective, the larger context must be addressed to improve societal and institutional engagement and broader social inclusivity. Racism and discrimination are significant issues to combat given their negative impacts on mental health (Shakya et al., 2010) and psychosocial functioning (Oxman-Martinez et al., 2012). Although it is beyond the scope of this paper to set out precise policy and programming that should be implemented, insights from this research and the wider literature suggest that attending to the responses and perceptions that residents of a receiving society hold is critical in promoting diversity 
and understanding (Guo et al., 2019; Ratković et al., 2017). Educating Canadians and targeting their negative perceptions about immigration would be beneficial given the increasing rates of resettled young people in Canada who have newcomer backgrounds; projections suggest this could be true for up to 49 percent of children under the age of 15 by 2036 (Statistics Canada, 2017b).

The need for more resources and supports that will enhance transition and adaptation into new systems continues to be evident as found in past research (Ratković et al., 2017). As schools are often one of the first points of contact to support newcomer well-being, professionals in the Canadian education system would benefit from training on culture and needs of newcomers to be able to provide welcoming and supportive spaces. Moreover, partnerships between mental health providers, community agencies (i.e. settlement workers) and schools would be ideal as such collaboration can help support youth adjustment and development (Li et al., 2017; Ratković et al., 2017).

Advice offered by the youth participants could be used in settlement agencies, schools, and mental health settings. Most youth participants had been in Canada for several years and have experienced and overcome many of the challenges that recently arrived youth face. Thus, settlement workers, educators, and clinicians may consider sharing the findings with recently arrived newcomer youth. Doing so may contribute to a sense of resilience and help newcomer youth through the adjustment process by validating stressors experienced and feelings of isolation (and even preparing youth for these obstacles), but also by affirming that challenges can be overcome with time and support.

Findings also revealed areas of focus to consider for programming with newcomer youth. For example, a focus on identity development and ethnic pride appears to be warranted as it can assist in the development of resiliency (d'Abreu et al., 2019). Findings additionally suggest that specific approaches to handling peer pressure would be useful to support newcomer youth well-being. As discussed by Chrismas and Chrismas (2017), pressure to "fit in" and be accepted by peers may put newcomer youth at greater risk for engagement in unhealthy behaviour (e.g. substance use, violence and aggression, and falling out of the school system). Methods for addressing bullying of newcomers should also be considered and built into school- and communitybased programming. Finally, more school and communitybased programs and activities that will facilitate socialization between newcomer youth and native-born peers to promote cross-cultural understanding and acceptance would be beneficial given that peer relationships and sense of belonging are important predictors of wellbeing (Crooks et al., 2021; Pieloch et al., 2016; Suárez-Orozco et al., 2009). For instance, peer mentoring programs that engage nativeborn peers and recently arrived youth at school could assist in creating a climate that is more supportive of newcomer youth (Birman \& Morland, 2014).

Future research should seek out perspectives of youth who do not attend immigrant-serving organizations and youth who do not speak the host language (with the assistance of an interpreter or in their first language) to look at the extent to which challenges are magnified or changed as a result of limited ability to express oneself in the language of the host country. In future studies, it would also be important to explore if function of status (immigrant vs. refugee) results in different factors of resilience and advice recommended by youth, given the different challenges experienced by those who come through different pathways (MacKay \& Tavares, 2005).

\section{Limitations}

The findings in the present study may not be generalizable to other newcomer youth in other settings and regions of the country; findings are best understood in relation to the experiences of newcomer youth living in mid-sized cities in Ontario, Canada who attend newcomer-serving organizations. The sample is also skewed toward female refugee youth from countries in the Middle East and therefore, may not speak to newcomer youth more broadly, and male immigrant youth in particular. Some youth in the sample who were not as proficient in English appeared to have difficulty expressing themselves at times, possibly limiting the perspectives and ideas shared, and even those youth who spoke more fluently may have been limited in their ability to express themselves fully at times. Finally, difference in experiences as a function of status (i.e. immigrant vs. refugee) were not examined.

\section{Conclusions}

Newcomer youth face many hardships when adapting to a new country that can affect their well-being and ability to develop meaningful and genuine relationships in their host country. Despite hardships, newcomer youth demonstrate resilience and develop coping skills and strategies to overcome challenges and lead meaningful lives. Findings align with previous literature, outlining major challenges experienced by newcomer youth, and contribute newcomers' advice and motivation to counteract these challenges. Participants acknowledged that the first years of resettlement are stressful and can feel isolating, but also encouraged youth to be brave, learn about Canada, reframe their thinking to be more positive, and access supports available to them. The necessity of addressing structural barriers and racism to support newcomer youths' well-being and social inclusion is indicated. 
Funding This work was supported by the Public Health Agency of Canada under Grant 1819-HQ-000052.

Data Availability N/A.

Code Availability N/A.

\section{Declarations}

Conflict of interest On behalf of all authors, the corresponding author states that there is no conflict of interest.

Ethical Approval All procedures performed involving human participants were in accordance with the ethical guidelines outlined by the Research Ethics Board at our institution and the national panel for ethical conduct for research involving humans.

Consent to Participate Parental consent and youth assent were obtained for youth 16 years and under. Youth 16 years and older signed a participant consent form.

Open Access This article is licensed under a Creative Commons Attribution 4.0 International License, which permits use, sharing, adaptation, distribution and reproduction in any medium or format, as long as you give appropriate credit to the original author(s) and the source, provide a link to the Creative Commons licence, and indicate if changes were made. The images or other third party material in this article are included in the article's Creative Commons licence, unless indicated otherwise in a credit line to the material. If material is not included in the article's Creative Commons licence and your intended use is not permitted by statutory regulation or exceeds the permitted use, you will need to obtain permission directly from the copyright holder. To view a copy of this licence, visit http://creativecommons.org/licenses/by/4.0/.

\section{References}

Anney, V. N. (2014). Ensuring the quality of the findings of qualitative research: Looking at trustworthiness criteria. Journal of Emerging Trends in Educational Research and Policy Studies, 5(2), 272-281.

Bagnoli, A., \& Clark, A. (2010). Focus groups with young people: A participatory approach to research planning. Journal of Youth Studies, 13(1), 101-119. https://doi.org/10.1080/1367626090 3173504

Beiser, M., Hou, F., Hyman, I., \& Tousignant, M. (2002). Poverty, family process, and mental health of immigrant children in Canada. American Journal of Public Health, 92(2), 220-227.

Bergnehr, D., \& Zetterqvist Nelson, K. (2015). Where is the child? A discursive exploration of the positioning of children in research on mental-health-promoting interventions. Sociology of Health \& Illness, 37(2), 184-197. https://doi.org/10.1111/1467-9566.12197

Betancourt, T. S., \& Khan, K. T. (2008). The mental health of children affected by armed conflict: Protective processes and pathways to resilience. International Review of Psychiatry, 20(3), 317-328. https://doi.org/10.1080/09540260802090363

Birman, D., \& Morland, L. (2014). Immigrant and refugee youth. In D. L. DuBois \& M. J. Karcher (Eds.), Handbook of youth mentoring (pp. 273-289). SAGE.

Boukpessi, T. B., Kpanake, L., \& Gagnier, J. P. (2021). Willingness to use mental health services for depression among African immigrants and white Canadian-born people in the province of Quebec,
Canada. Journal of Immigrant and Minority Health, 23(2), 320 328. https://doi.org/10.1007/s10903-020-01061-y

Braun, V., \& Clarke, V. (2006). Using thematic analysis in psychology. Qualitative Research in Psychology, 3(2), 77-101. https://doi.org/ 10.1191/1478088706qp063oa

Chrismas, B., \& Chrismas, B. (2017). What are we doing to protect newcomer youth in Canada, and help them succeed? Journal of Community Safety and Well-Being, 2(3), 87-90.

Clarke, V., Braun, V., \& Hayfield, N. (2015). Thematic Analysis. In J. A. Smith (Ed.), Qualitative psychology: A practical guide to research methods (pp. 222-248). SAGE Publications.

Costigan, C., Koryzma, C., Hua, J., \& Chance, L. (2010). Ethnic identity, achievement, and psychological adjustment: Examining risk and resilience among youth from immigrant Chinese families in Canada. Cultural Diversity and Ethnic Minority Psychology, 16(2), 264-273. https://doi.org/10.1037/a0017275

Crooks, C. V., Kubishyn, N., Noyes, A., \& Kayssi, G. (2021). Engaging peers to promote wellbeing and inclusion of newcomer students: A call for equity-informed peer interventions. Psychology in the Schools. https://doi.org/10.1002/pits.22623

Child and Youth Refugee Research Coalition (CYRRC) (2018). Demographic \& Socioeconomic Characteristics. http://cyrrc. org/data-aggregation/demographic-socioeconomic-characteri stics/

d'Abreu, A., Castro-Olivo, S., \& Ura, S. K. (2019). Understanding the role of acculturative stress on refugee youth mental health: A systematic review and ecological approach to assessment and intervention. School Psychology International, 40(2), 107-127. https://doi.org/10.1177/0143034318822688

Derluyn, I., \& Broekaert, E. (2007). Different perspectives on emotional and behavioural problems in unaccompanied refugee children and adolescents. Ethnicity and Health, 12, 141-162. https:// doi.org/10.1080/13557850601002296

Edge, S., Newbold, K. B., \& McKeary, M. (2014). Exploring sociocultural factors that mediate, facilitate, and constrain the health and empowerment of refugee youth. Social Science and Medicine, 117, 34-41. https://doi.org/10.1016/j.socscimed.2014.07.025

Este, D., \& Van Ngo, H. (2011). A resilience framework to examine immigrant and refugee children and youth in Canada. In S. S. Chuang \& R. P. Moreno (Eds.), Immigrant children: Change, adaptation, and cultural transformation (pp. 27-50). Lexington Books.

Goodman, J. H. (2004). Coping with trauma and hardship among unaccompanied refugee youths from Sudan. Qualitative Health Research, 14, 1177-1196. https://doi.org/10.1177/1049732304 265923

Guo, Y., Maitra, S., \& Guo, S. (2019). "I belong to nowhere": Syrian refugee children's perspectives on school integration. Journal of Contemporary Issues in Education, 14(1), 89-105. https://doi. org/10.20355/jcie29362

Hadfield, K., Ostrowski, A., \& Ungar, M. (2017). What can we expect of the mental health and well-being of Syrian refugee children and adolescents in Canada? Canadian Psychology/psychologie Canadienne, 58(2), 194-201. https://doi.org/10.1037/cap0000102

Hamilton, H. A., Noh, S., \& Adlaf, E. M. (2009). Adolescent risk behaviours and psychological distress across immigrant generations. Canadian Journal of Public Health, 100(3), 221-225. https://doi.org/10.1007/BF03405545

Immigration, Refugees, and Citizenship Canada. (2020). Departmental Plan 2020-2021. Government of Canada. https://www.canada. $\mathrm{ca} / \mathrm{en} / \mathrm{immigration}$-refugees-citizenship/corporate/publicationsmanuals/departmental-plan-2020-2021/departmental-plan.html

James, A. (2007). Giving voice to children's voices: Practices and problems, pitfalls and potentials. American Anthropologist, 109(2), 261-272. https://doi.org/10.1525/aa.2007.109.2.261 
Juang, L. P., Simpson, J. A., Lee, R. M., Rothman, A. J., Titzmann, P. F., Schachner, M. K., \& Betsch, C. (2018). Using attachment and relational perspectives to understand adaptation and resilience among immigrant and refugee youth. American Psychologist, 73(6), 797-811. https://doi.org/10.1037/amp0000286

Kirmayer, L. (2014). Forward. In L. Simich \& L. Andermann (Eds.), Refuge and Resilience: Promoting resilience and mental health among resettled refugees and forced migrants (pp. vii-ix). Springer.

Kirmayer, L. J., Weinfeld, M., Burgos, G., du Fort, G. G., Lasry, J. C., \& Young, A. (2007). Use of health care services for psychological distress by immigrants in an urban multicultural milieu. The Canadian Journal of Psychiatry, 52(5), 295-304. https://doi.org/ 10.1177/070674370705200504

Li, X., Que, H., \& Power, K. (2017). Welcome to "the rock": Service providers' views on newcomer youth integration in Newfoundland and Labrador. Journal of International Migration and Integration, 18(4), 1105-1122.

Liebenberg, L., \& Theron, L. (2015). Innovative qualitative explorations of culture and resilience. In L. Theron, L. Liebenberg, \& M. Ungar (Eds.), Youth Resilience and Culture-Commonalities and Complexities (pp. 203-216). Springer.

Liegghio, M., Nelson, G., \& Evans, S. D. (2010). Partnering with children diagnosed with mental health issues: Contributions of a sociology of childhood perspective to participatory action research. American Journal of Community Psychology, 46(1-2), 84-99. https://doi.org/10.1007/s10464-010-9323-Z

MacKay, T., \& Tavares, T. (2005). Building hope: Appropriate programming for adolescent and young adult newcomers of waraffected backgrounds and Manitoba Schools. Manitoba Education, Citizenship and Youth.

Mawani, F. N. (2014). Social determinants of refugee mental health. In L. Simich \& L. Andermann (Eds.), Refuge and Resilience (pp. 27-50). Springer.

Ontario Centre of Excellence for Child and Youth Mental Health. (2015). Taking action on health equity and diversity: Responding to the mental health needs of children, youth and families new to Canada. Available: http://www.excellenceforchildandyouth.ca/ sites/default/files/resource/policy_newcomer_cymh.pdf.

Oxman-Martinez, J., Rummens, A. J., Moreau, J., Choi, Y. R., Beiser, M., Ogilvie, L., \& Armstrong, R. (2012). Perceived ethnic discrimination and social exclusion: Newcomer immigrant children in Canada. American Journal of Orthopsychiatry, 82(3), 376-388. https://doi.org/10.1111/j.1939-0025.2012.01161.x

Pickren, W. E. (2014). What is resilience and how does it relate to the refugee experience? Historical and theoretical perspectives. In L. Simich \& L. Andermann (Eds.), Refuge and Resilience (pp. 7-26). Springer.

Pieloch, K. A., McCullough, M. B., \& Marks, A. K. (2016). Resilience of children with refugee statuses: A research review. Canadian Psychology/psychologie Canadienne, 57(4), 330-339. https://doi. org/10.1037/cap0000073

Ratković, S., Kovačević, D., Brewer, C. A., Ellis, C., Ahmed, N., \& Baptiste-Brady, J. (2017). Supporting refugee students in Canada: Building on what we have learned in the past 20 years. Report to Social Sciences and Humanities Research Council of Canada. St. Catharines: Brock University

School Mental Health-Assist (2016, January 21). Welcoming Syrian Newcomer Students \& Families to School - INFO-SHEET. https://smh-assist.ca/blog/welco ming- syrian-newcomer-students-families-to-school-info-sheet/
Selimos, E. D., \& George, G. (2018). Welcoming initiatives and the social inclusion of newcomer youth: The case of Windsor. Ontario. Canadian Ethnic Studies, 50(3), 69-89.

Shakya, Y. B., Khanlou, N., \& Gonsalves, T. (2010). Determinants of mental health for newcomer youth: Policy and service implications. Canadian Issues, 98-101. https://acs-aec.ca/wp-content/ uploads/2019/05/CITC-2010-Summer-Ete-L-1.pdf\#page $=100$

Shamrova, D. P., \& Cummings, C. E. (2017). Participatory action research (PAR) with children and youth: An integrative review of methodology and PAR outcomes for participants, organizations, and communities. Children and Youth Services Review, 81, 400-412. https://doi.org/10.1016/j.childyouth.2017.08.022

Shenton, A. K. (2004). Strategies for ensuring trustworthiness in qualitative research projects. Education for Information, 22(2), 63-75. https://doi.org/10.3233/EFI-2004-22201

Smithson, J. (2000). Using and analysing focus groups: Limitations and possibilities. International Journal of Social Research Methodology, 3(2), 103-119. https://doi.org/10.1080/136455700405172

Statistics Canada (2017b). Immigration and ethnocultural diversity: Key results from the 2016 Census. https://www150.statcan.gc. $\mathrm{ca} / \mathrm{n} 1 /$ daily-quotidien/171025/dq171025b-eng.htm

Statistics Canada. (2017a). Population growth: Migratory increase overtakes natural increase. https://www.statcan.gc.ca/pub/11-630x/11-630-x2014001-eng.htm

Stewart, D. W., \& Shamdasani, P. N. (2014). Focus groups: Theory and practice (Vol. 20). Sage.

Suárez-Orozco, C., Pimentel, A., \& Martin, M. (2009). The significance of relationships: Academic engagement and achievement among newcomer immigrant youth. Teachers College Record, 111(3), 712-749.

Ungar, M. (2008). Resilience across cultures. The British Journal of Social Work, 38(2), 218-235. https://doi.org/10.1093/bjsw/bcl343

United Nations High Commissioner for Refugees. (2018). Global trends: Forced Displacement in 2018. https://www.unhcr.org/ 5d08d7ee7.pdf

Vang, Z. M., Sigouin, J., Flenon, A., \& Gagnon, A. (2017). Are immigrants healthier than native-born Canadians? A systematic review of the healthy immigrant effect in Canada. Ethnicity \& Health, 22(3), 209-241. https://doi.org/10.1080/13557858.2016.1246518

Woodley, T., Majzoub, S., Gallo, M., Alsaieq, M., Ross, G. (2018). A grave problem: EKOS survey on Islamophobia in Canada [Data Set]. The Canadian Muslim Forum \& Canadians (FMC-CMF) for Justice and Peace in the Middle East (CJPME) https://d3n8a 8pro7vhmx.cloudfront.net/cjpme/pages/4101/attachments/origi nal/1517850987/CJPME-CMF_Survey_on_Islamophobia_-2018-02-06-FINAL.pdf?1517850987

World Health Organization. (2019, October 23) Adolescent Mental Health. https://www.who.int/news-room/fact-sheets/detail/adole scent-mental-health

Xu, M. A., \& McDonald, J. T. (2010). The mental health of immigrants and minorities in Canada: The social and economic effects. Canadian Issues, 29-31. Retrieved from http://ezproxy.lib.ucalg ary.ca:2048/login?url=http://search.proquest.com/docview/76316 1582 ? accountid $=9838$

Publisher's Note Springer Nature remains neutral with regard to jurisdictional claims in published maps and institutional affiliations. 